\title{
Case Studies of 17 Patients
}

\section{Salerian $\mathrm{AJ}^{*}$}

Salerian Centre For Neuroscience and Pain, USA

${ }^{*}$ Corresponding author: Salerian AJ, Salerian Centre For Neuroscience and Pain, 8409 Carlynn Dr., Bethesda, MD 20817, USA, E-mail: alensalerian@gmail.com

Citation: Salerian AJ (2015) Case Studies of 17 Patients. J Case Rep Stud 3(2): 203. doi: 10.15744/23489820.2.503

Received Date: January 25, 2015 Accepted Date: April 01, 2015 Published Date: April 08, 2015

Abstract
Background: Heightened risk of adverse events following opiate discontinuation has been reported.

Findings: This retrospective review of 17 patients suggests an increased risk of adverse events including premature death with opiate discontinuation long after withdrawal stage. The results are consistent with previously reported yet not fully understood - opiate associated neuro protective mechanism - against premature death for some vulnerable subgroups.

Conclusion: For some vulnerable people termination of opiates - regardless of why or how - may represent a heightened risk of premature death.

Keywords: Opiates; Addiction; Pain; Withdrawal; Premature death

\section{Findings}

This study suggests an increased risk of adverse events including premature death following opiate discontinuation long after withdrawal stage.

\section{Case studies of 17 patients}

\section{Information}

In general people with dual diagnosis - psychiatric and substance use disorders - may represent a high risk of premature death consistent with the study by Grant et al [1]. Kakko and colleagues reported 20\% death rate among patients taking buprenorphine versus $0 \%$ death in a control group in one year [2]. There is also compelling neuroimaging evidence of neurodegeneration and brain atrophy associated in chronic pain patients who are often treated with opiates [3]. Risk of death associated with opioid treatment or dependence has been a subject of controversy. The validity of opioids related vital statistics due to recording errors has also been raised [4].

\section{The focus of this study is narrow}

To review clinical states of 17 patients in 12 months following discontinuation of treatment triggered by the temporary closure of a treatment center. Prior to their discharge, 17 patients were stable on opioids without any life-threatening medical conditions. No evidence of potential suicidal behavior, overt signs of depression or functional impairment were observed in medical records.

All patients had appropriate referrals for follow up. For unknown reasons not all patients received follow-up treatment with opiates. All patients were informed of potential risk of adverse events associated with discontinuation of treatment.

\section{Method}

Medical records of 17 patients at the treatment center were reviewed. Routine documentation included DSM-IV based diagnosis and pain - mood assessment on a scale of 1 to 10 with 1 representing the worst and 10 representing the best response. This was the essential measure. Also reviewed were follow-up medical records. Brief phone evaluations were completed for patients who did not receive follow-up care. Vital statistics were obtained from official documents and death notices. Opiates included oxycodone, methadone, oxymophone, fentanyl.

\section{Results}

10 patients received follow-up care. 7 patients did not receive follow-up care. Among 10 patients receiving follow-up care 1 patient was off opiates (Table 1).

The youngest was age 22 and the oldest age 57, 10 men and 7 women. The primary diagnosis of 12 patients was chronic pain versus 5 with dual diagnosis of pain, addiction or treatment resistant depression. 


\begin{tabular}{|c|c|c|c|c|}
\hline Patients & Age & Race & Gender & Follow up And opiates \\
\hline 1 & 57 & AA & F & NO \\
\hline 2 & 22 & C & M & YES \\
\hline 3 & 37 & C & M & YES \\
\hline 4 & 33 & C & F & YES \\
\hline 5 & 57 & C & M & NO \\
\hline 6 & 20 & C & M & YES \\
\hline 7 & 50 & C & M & NO \\
\hline 8 & 21 & C & F & NO \\
\hline 9 & 37 & C & F & YES \\
\hline 10 & 37 & C & M & NO \\
\hline 11 & 45 & C & F & YES \\
\hline 12 & 46 & AA & F & NO \\
\hline 13 & 50 & C & M & YES \\
\hline 14 & 30 & C & M & YES \\
\hline 15 & 45 & AA & M & NO \\
\hline 16 & 40 & AA & F & YES \\
\hline 17 & 45 & C & M & NO \\
\hline
\end{tabular}

Table 1: Demographics of 17 patients

Patients who did not take opiates reported worsening of mood and pain scores. There were two fatalities both receiving outpatient treatment. 1 by suicide and 1 from postsurgical complications.

\section{Review of two fatalities}

Patient 1: Age 22, three months after reduction of opiates while attending an outpatient methadone clinic, this college student committed suicide. On the day of suicide he was evaluated in an emergency room for depression and suicidality and referred back to the methadone clinic.

Patient 2: This 57-year-old woman died of postsurgical complications of exploratory surgery for abdominal pain 7 months post termination of treatment. She was receiving care but her methadone was discontinued.

A preliminary report 1 year post intervention suicides among patients at the center may also merit special mention. Out of 1200 total patient population 398 patients were discharged. Among them, there were 7 fatalities from suicides. This represented a 20 fold increase of self-inflicted deaths (Table 2).

\begin{tabular}{|c|c|c|}
\hline Patient & $\begin{array}{l}\text { With opiates } \\
\text { Mood-Pain Score }\end{array}$ & $\begin{array}{l}\text { Without opiates } \\
\text { Mood-Pain Score }\end{array}$ \\
\hline 1 & 5.9 & 2 \\
\hline 2 & 6.5 & \\
\hline 3 & 6.3 & \\
\hline 4 & 7 & \\
\hline 5 & 6.2 & 2.5 \\
\hline 6 & 6.8 & \\
\hline 7 & 5.9 & 2.5 \\
\hline 8 & 7.1 & 3.1 \\
\hline 9 & 6.6 & \\
\hline 10 & 7.5 & 3.2 \\
\hline 11 & 6.3 & \\
\hline 12 & 6.5 & 2.5 \\
\hline 13 & 6 & \\
\hline 14 & 7.2 & \\
\hline 15 & 6.1 & 2.5 \\
\hline 16 & 6.6 & \\
\hline 17 & 6.3 & 2.7 \\
\hline Average & 6.4 & 2.9 \\
\hline
\end{tabular}

Table 2: Mood-Pain scores of 17 patients with opiates Vs without opiates 


\section{Discussion}

The retrospective nature and small sample size are major limitations for this study. The findings are consistent with previously published reports by Kakko and Grant of heightened risk of premature death among people with discontinued opiate treatment $[1,2]$.

Noteworthy are the 2 premature fatalities in a small group of 17 patients within one year termination of opiate treatment. The delayed occurrence of both fatalities - 3 and 7 months post termination is consistent with the observation that for these two individuals opiates might have been neuroprotective against premature death.

\section{Conclusion}

The review results are consistent with the safety and efficacy of opiates for chronic pain, addiction and complex psychiatric disorders. Healthcare professionals must be sensitized to the heightened risk of premature death upon discontinuation of stable treatment with opiates.

\section{References}

1. Grant BF, Stinson FS, Dawson DA, Chou SP (2004) Prevalence and co-occurrence of substance use disorders and independent mood and anxiety disorders: results from the National Epidemiologic Survey on Alcohol and Related Conditions. Arch Gen Psychiatry 61: 807-16.

2. Kakko J, Svanborg D K, Kreek MJ, Hellig M (2003) 1-year retention and social function after buprenorphine-assisted relapse prevention treatment for heroin dependence in Sweden: a randomised, placebo-controlled trial. Lancet 361: 662-8.

3. Apkarian AV, Sosa Y, Sonty S, Levy RM, Harden RN, et al. (2004) Chronic back pain is associated with decreased prefrontal and thalamic gray matter density. J Neurosci 24: 10410-5.

4. Webster LR, Dasgupta N (2011) Obtaining adequate data to determine causes of opioid related overdose deaths. Pain Med 2: S86-92. 